\title{
The Effectiveness of Implementing Environmental Management System - ISO 14001 in Food Manufacturing Companies: A Case Study of a Sri Lankan Food Manufacturing Company
}

\author{
K. M. S. C. Kumara \\ Systems Certification Division, Sri Lanka Standards Institution \\ Elvitigala Mawatha, Colombo 08, Sri Lanka \\ E-mail: konarasus@gmail.com
}

\begin{abstract}
T. K. Weerasinghe
Centre for Environmental Studies and Sustainable Development

The Open University of Sri Lanka, Nawala, Nugegoda, Sri Lanka

E-mail: tkwee@ou.ac.lk
\end{abstract}

Received: June 17, 2017 Accepted: July 7, 2017

doi:10.5296/emsd.v6i2.11413ＵRL: https://doi.org/10.5296/emsd.v6i2.11413

\begin{abstract}
This paper aims to explore how an Environmental Management System (EMS) based on ISO 14001 would assist to enhance the performance of a Food Manufacturing Company. The research objectives were to assess the current environmental aspects and related impact and define mitigation measures to minimize such aspects while focusing on the applicable legislative requirements for the industry and the existing mitigation measures. Different types of waste generated during the processes were identified based on United Nations Environmental Plan (UNEP) cleaner production methodology and baseline data related to waste generation were analysed using Pareto charts. An Environmental Aspect Impact Register was prepared for each division to identify environmental hazards based on risk assessment criteria given in ISO 31010 Standard and the results compared before and after risk levels using the T- test.
\end{abstract}

Analysis of the environmental aspect impact register results concluded that implemented 
mitigation measures were effective on particular causes at $95 \%$ confidence level and adopting Environmental Management Systems (EMS) in this company had made a positive impact on the identified performance indicators including environmental performance indicators and financial indicators. It further recognized that there was more positive impact on water saving as the quantity of water used in the manufacturing processes had already reduced.

Keywords: Environment Management System, Food Manufacturing Company, Environmental Performances

\section{Introduction}

Environmental issues have become a global concern in the recent decades. Most of the environmental issues and challenges are related to continuous consumption of materials, energy and water by companies, resulting in the depletion of these resources. In addition, uncontrolled emission of toxic gases, wastes and effluents into soil, water and air by the companies also has adverse effects on the environment. Climate change, global warming, ozone depletion and nitrifications, are some of the well-known consequences of these negative environmental impacts of activities of manufacturing industries on the environment.

The Environmental impacts by companies are now attracting serious concerns from the public, government, business, media and other stakeholders. The need for changes in environmental legislation and standards has begun to gain greater acceptance more prominence in public debates. Many environmental pressure groups have gradually emerged calling for a healthier environment (Bohdanowicz, 2003).

There has been a growing trend for companies to become certified with a formal Environmental Management System (EMS). Much research has been carried out on the benefits of environmental management systems which have typically been on companies either manufacturing or having an industrial background (Biondi et al., 2000). However, Howes et al., (2006) argues that an ISO certified company delivers real environmental improvements, usually as a byproduct of the attention that it focuses on material use and waste management. In order to address the skepticism surrounding the effectiveness of the standard as a tool to enhance sustainable environmental management, research was carried out at USEA in Zimbabwe. Moreover, Yarnell (1993) argued that employee training and awareness were key strategies in the implementation of an integrated EMS and ultimately an improved corporate environmental performance. The ISO 14001 standard defines an EMS as "a management tool enabling an organization of any size or type to control the impact of its activities, products or services on the environment". The ISO 14001 establishes a framework for managing the environmental aspects of an organization through the development of formal processes and procedures. The standard contains 17 key elements grouped into five major areas: environmental policy, planning, implementation and operation, checking and corrective action, and management review. A unique feature of the system is that it is developed to be appropriate for any company, regardless of industry, size, location, and the level of their environmental responsibilities. The ISO 14001 is a voluntary, consensus-based, and market-driven standard (Kloepfer, 1997). 
Food processing industries have a large impact on the economy and the country in general. The concentration of the industries in such a small area has aggravated the environmental stress caused by industrial activities. Some of the major problems include industrial liquid and solid waste, air and water pollution. An organization should ensure that any significant impact is appropriately controlled and/or reduced. The impacts and aspects should then be checked against a legal register to establish which items of environmental legislation are applicable to the organization when implementing an EMS.

Environmental performance should therefore be measured against the organization's control of its operations and how these are tied into and comply with any relevant environmental legislation along with the recorded reduction and minimization of overall environmental impact to enhance environmental performance while applying such mitigation measures. In theory, an adequately scoped EMS should encompass all impacts. Finally, that will evaluate the extent of compliance with the applicable legislative measures with respect to environmental pollution.

Several studies that have been conducted related to ISO 14001 and waste reduction includes a study by Rondinelli and Vastag (2000). In their study, they found that ISO 14001 certification encouraged employees to think of material recycling and to increase their commitment to sustainable management. Additionally, during the period following the achievement of ISO 14001, the amount of waste that had to be sent to landfills was reduced from 7608 tons to 4960 tons within three years and the waste cost of production per ton of aluminum dropped from $\$ 8.33$ to $\$ 6.50$. Most of the ISO 14001 studies do not focus on solid waste reduction, but on comprehensive environmental performance improvement or other aspects (Matthewe, 2011). ISO14001 and its benefits to organizations are well researched. The most immediate benefits of the approach are that its correct use will lead to more efficient use of key energy types and materials. This in turn will lead to a reduction in the waste outputs that an organization will produce and the consequent reduction of costs (Pinero and Mason,1998). Another key benefit of ISO 14001 is that it is a well-recognized international standard and the ISO itself is well respected in general. Consumers in general who are knowledgeable and have an awareness of ISO 14001 may feel assured by conformance to the standard and its ethical intentions. ISO 14001 also gives an organization the mandate to control its environmental aspects and impacts on its own processes, products, and services. It could be said that in many circumstances nobody knows their business and resulting wastes better than the organizations themselves. This allows the internal experts to control the situation not some outside body who does not understand their business and intricacies (Marsh and Perera, 2012).

\subsection{Area of Investigation}

In this research, Edinborough Products (Pvt) Ltd (EPPL) has been selected, as it has been manufacturing different types of food products by using natural raw material. The same company has a filling plant of bottled drinking water inside the same premises which produces large quantities of bottled water in different volumes. Further, it has an internal PET (Poly Ethylene Tetrathalate) bottle production plant which produces nearly 100,000 PET 
bottles per month, two furnace oil boilers, and two diesel generators causing number of environmental impacts.

As a food processing company, Edinborough Products Pvt Ltd (EPPL) also has a significant impact on the environment on account of solid wastes, even though efforts have been made to reduce waste generation. As a legal obligation, it is imperative that the Environmental Protection License (EPL) should be obtained for the entire manufacturing plant.

Edinborough Products (Pvt) Ltd is now considering sustainability and environmental management issues to the extent of including them in the objectives and goals of the organization due to economic and non-economic incentives. The organization is now adopting Environmental Management Systems (EMS) and has already obtained the International Organization for Standardization (ISO) certification for Quality Management System (ISO 9001) and Food Safety Management System (ISO 22000) which basically covers the management aspects including policy, internal audit and the management review.

Since the EPPL has already obtained the Environmental Protection Licenses (EPLs) from the Central Environmental Authority (CEA), Sri Lanka, it has already established mitigation measures with respect to the pollution caused by wastewater and contaminated emissions due to the furnace oil boilers. They also have a well-functioning Sewage Water Treatment Plant (SWTP) and the verification of discharge quality has been done by the CEA nominated external laboratories as per the stipulated frequencies given in the annex of the EPL. Also the air emissions by the furnace oil boilers have also been monitored for particulate matter (PM), $\mathrm{CO}$ and $\mathrm{SO}_{2}$ as per the regulation with external laboratory testing as requested by the CEA.

The general purpose of this paper is to study the impact of ISO 14001 and other significant factors on solid waste generation rates of organizations. The present research mainly focuses on how solid waste management and cleaner production aspects based on ISO 14001 would enhance environmental performance of a food manufacturing company so as to meet customer demand in a sustainable manner.

\section{Methodology}

Different types of solid waste generated were identified during company production process under two categories: organic and non-organic waste in kilo grams per month from February to August 2016. According to the UNEP cleaner production methodology, baseline data related to waste generation including the usage of water by different processes were collected and analyzed with the help of process flow diagrams. Pareto analysis was used to identify the departments which contribute $80 \%$ of solid wastes. Generated waste was categorized and prioritized using Pareto principles (that specifies an unequal relationship between inputs and outputs) to identify the main hazards which cause a significant environmental impact.

Environmental management programmes were planned and implemented after identifying the initial status of wastes with the aim of improving environmental performance. An Environmental Aspect Impact Register was prepared for each division to identify environmental hazards based on Risk Assessment criteria given in ISO 31010. All applicable legislative requirements have been reviewed and evaluated by focusing on a related 
regulatory frame under the National Environmental Act (NEA) of Sri Lanka. An assessment of effectiveness of mitigation measures was done using the t-test (at 95\%). A comparative Pareto analysis was also conducted to ascertain in the reduction of amount of waste generated after implementing the mitigation measures and the cost incurred due to waste and waste management activities were compared.

\section{Results and Discussion}

Waste production baseline data are given below in Table 1 .

Table 1 - Amount of Waste Production per month

\begin{tabular}{|l|l|l|l|}
\hline \multirow{2}{*}{ Month } & \multicolumn{3}{|l|}{ Amount of waste production per month $(\mathbf{k g})$} \\
\cline { 2 - 4 } & Organic & Non-organic & Total \\
\hline February & 1004.26 & 159.13 & 1163.39 \\
\hline March & 1277.98 & 202.51 & 1480.49 \\
\hline April & 513.32 & 81.34 & 594.66 \\
\hline May & 1004.87 & 159.23 & 1164.09 \\
\hline June & 843.18 & 133.61 & 976.79 \\
\hline July & 737.47 & 116.86 & 854.33 \\
\hline August & 744.76 & 118.01 & 862.78 \\
\hline
\end{tabular}

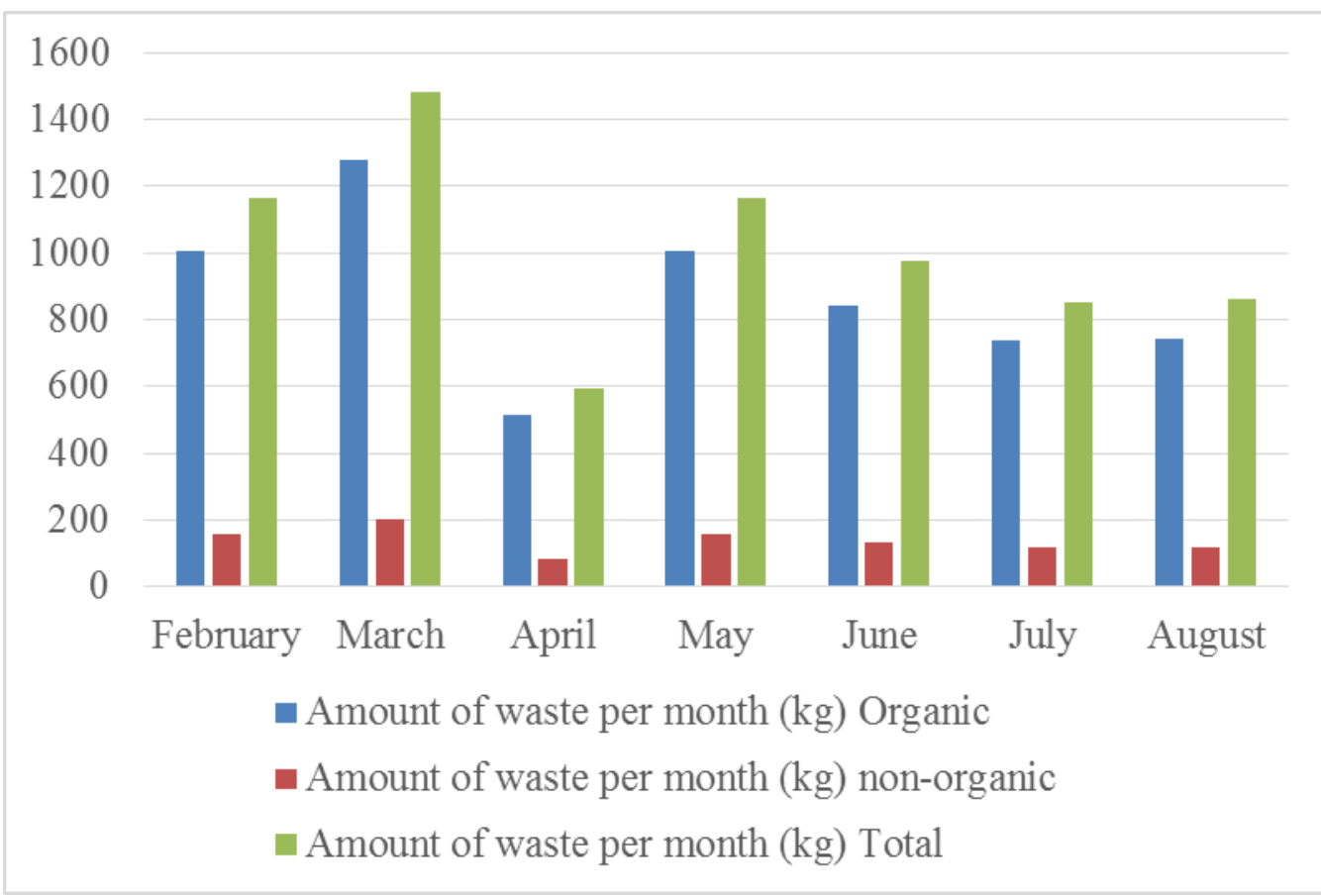

Figure 1- Amount of Waste Production per Month from February to August 2016

When analyzing the data with regard to departments' contribution to waste generated, the highest amount of waste (15342.2 kg per month) was produced by the soya department and it was nearly $66 \%$ of the total waste production of a month. Apart from that, the factory garden and the jam factory also produced a considerable amount of both organic and non-organic waste. Waste soya from the soya factory was the highest amount of organic waste produced 
from factory operation. Fruit peels from the jam factory and grass cuttings from the factory garden were also in considerable amounts. From among non-organic waste amounts, High Density Polythene (HDPE) was the highest during the production process (Table 2).

Table 2 - Total weight of waste generated from each department

\begin{tabular}{|l|l|}
\hline Responsible Department & Total weight of Waste generated (kg) \\
\hline Jam Department & 1821 \\
\hline Packing Area & 26 \\
\hline Factory & 600 \\
\hline Laboratory & 13 \\
\hline Soya Factory & 15342.2 \\
\hline Water Plant & 220 \\
\hline Finished Goods Store & 265 \\
\hline Kojji Room & 17 \\
\hline Grinding Room & 11.56 \\
\hline Vinegar Yard & 57 \\
\hline Pet Plant & 153.06 \\
\hline Maintenance Workshop & 0 \\
\hline Kitchen \& Canteen & 447 \\
\hline Store No 1 & 140 \\
\hline Store No 2 & 12 \\
\hline Main Office & 23.2 \\
\hline Factory Garden Waste & 4120 \\
\hline
\end{tabular}

Total Waste amount produced against responsible dept.

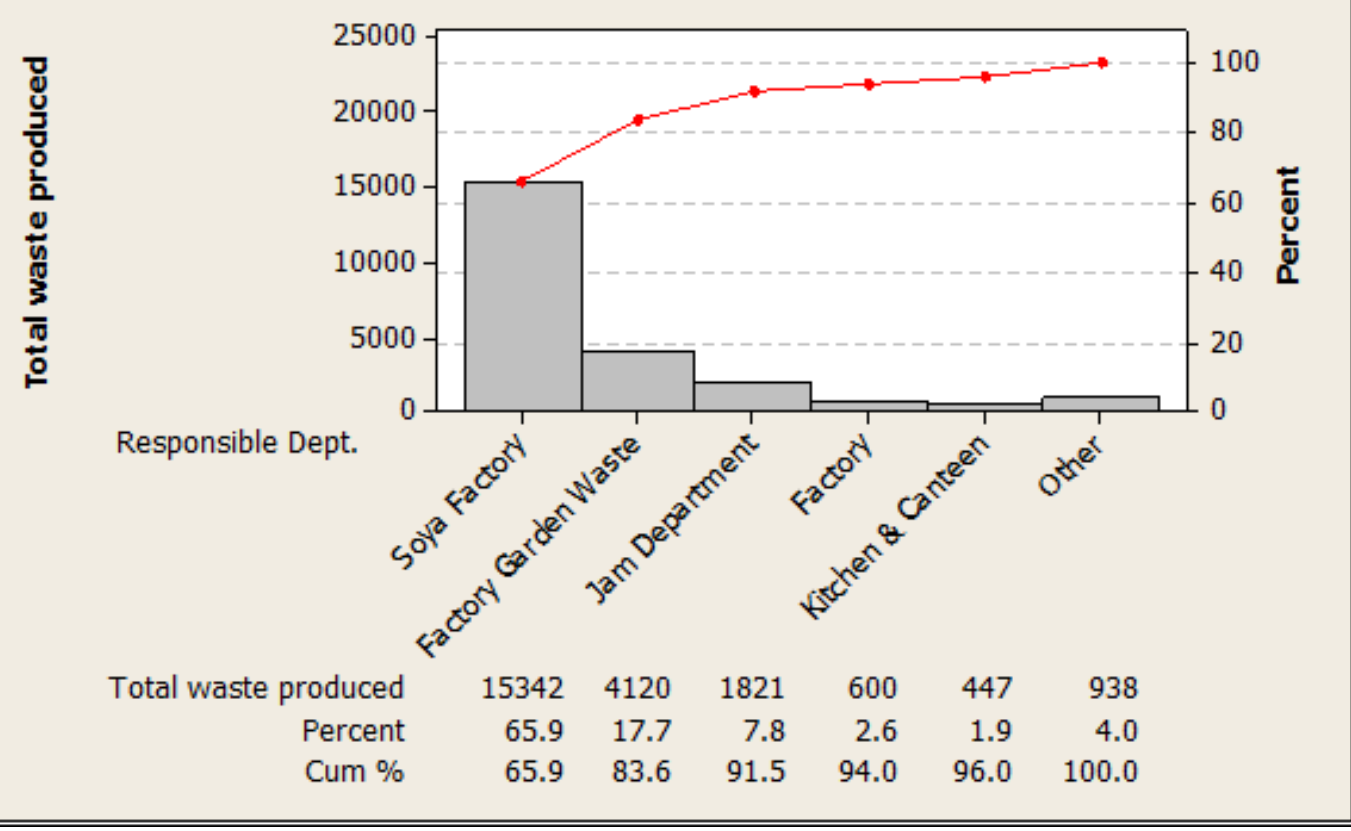

Figure 2. Pareto Chart for total weight of waste generated per month from different departments 
After analyzing the baseline data according to UNEP cleaner production methodology and using Pareto analysis, the main departments which cause a significant impact on the environment were identified. The soya factory and the factory garden generated the highest amount of waste representing $80 \%$. Therefore, it is clear from the data that the cumulative percentage of waste has reached $83.6 \%$ thus indicating significant environmental impact due to those two departments with respect to solid waste generation (Fig. 2).

From the total waste produced from the factory, more than $80 \%$ was organic or degradable waste (Fig. 1). Composting of that waste is an acceptable mitigation measure to improve environmental performance and the compost produced could be used for organic farming within the same premises.

A newly constructed containment tank for furnace oil storage is another mitigation measure for oil waste management. Further, awareness programmes for factory workers could also be conducted to minimize waste generation and promote effective waste recycling. In addition, segregation mechanisms have also been implemented as the most significant mitigation measure for waste management.

Other than waste generation, the total water usage has also been taken into account as it is a very important environmental factor. Water which was mostly used for washing and cleaning purposes sometimes mixed with detergents, may become a major source of impact on the environment. To minimize such an environmental impact, the quantity of detergents used for cleaning purposes was revalidated and sent to a wastewater treatment plant for clean up before discharging to the environment.

Further, in order to achieve the target for water usage, several programmes have been conducted and process improvements have been implemented. Special awareness has been generated with posters displayed at relevant places highlighting the proper usage of water in an effective manner.

Flow meters were also installed for each of the production processes in order to monitor their water usage. Spray guns were provided instead of normal hoses to achieve minimal usage of water for internal processes resulting in a significant reduction of water usage. Further, it enhanced the Sewage Water Treatment Plant life time as well.

When preparing the Environmental Aspect Impact Register, the guidance given in the ISO 14001 was used and risk assessments were carried out as per the guidance given in the ISO 31010. When analyzing these aspects, it is clear that the implemented control measures such as composting of organic solid waste significantly reduced the risk value from 10 to 5 having a t value of 0.000 at $95 \%$ confidence level. This result clearly indicated that implemented mitigation measures were effective.

The effectiveness of the EMS has been studied throughout the world by different researchers; by analyzing environmental aspects and impact. A study observed that electronic firms that adopted ISO 14001 were able to improve up to the industry best practices (Russo, 2000).

Another study conducted in the auto-motive supply sector before Ford and General Motors 
required their suppliers to be ISO certified and found minimal reductions after ISO 14001 adoption. In terms of toxic releases and compliance with regulatory requirements, environmental performance was about the same in facilities that had adopted EMSs under ISO 14001 and those that had not (Matthews, 2001).

Eleven large companies in Guadalajara, Mexico, signed a voluntary agreement with Mexico's Ministry of Environment and Natural Resources to mentor small suppliers in implementing EMSs. Within three months of completing the formal EMS training based on the ISO 14001 model, over $80 \%$ of the participating companies in the study had reduced their environmental releases, nearly $70 \%$ had improved their work environment, and over 50\% had improved their economic performance (Successful Practices of EMS in SMEs- North American Perspectives, Commission of Environmental Cooperation, 2005).

The project report noted that the vast majority of the "root causes" of significant environmental problems identified by the firms could be addressed through changes in management practices such as improved maintenance, improved procedures and better training. Relatively few of the solutions, according to the report, required significant capital expenditures (Lexington Group, 2002).

Therefore, it is clear that implementing effective mitigation measures after analyzing the impact and related aspects could achieve a successful output.

\section{Conclusion}

When analyzing the risk factor mark allocation in the environmental aspect impact register, it is clear that the risk marks allocated for each environmental aspect before implementing defined control measures are always higher than those after implementing. This finding basically concludes that the mitigation actions implemented by the organization show an effective reduction of environmental impact. Based on the $t$ value, it is clear that the reduction is significant.

This study further highlighted that the control measures taken such as the establishment of containment oil tanks for furnace oil storage have improved environmental performance as the ISO 14001 management tool allows an organization of any size and type to control the impact of its activities, products or services on the environment.

A considerable financial benefit has also been achieved by EPPL after implementing ISO 14001. After safe categorization and composting of solid waste, the company has stopped the outsource operation and has gained financial outcome of nearly Sri Lankan Rs. 1.2 million. Furthermore, Edinborough Products Pvt. Ltd has gained third-party recognition as well as ensured environmental sustainability while improving performance.

\section{References}

Biondi, V., Frey, M., \& Iraldo, F. (2000). Environmental management systems and SMEs. Greener Management International, 29, 55-69

Bohdanowicz, P. (2003). A study of environmental impacts, environmental awareness and 
pro-ecological initiatives in the hotel industry, Energimyndigheten, 21, 63-69

Howes, J., John, D. W., \& Minard, R. A. Jr. (2006). Resolving the Paradox of Environmental Protection. http:www.issues.org/14.4/howes.htm.

ISO 31010: (2016). Risk Management- Risk Assessment Techniques. International Standard, $01,7-86$

ISO 14001, (2004). Environmental managemant systems- requirements with guidance for use. International Standard, 3, 1-18.

Kloepfer, R. J. (1997). Will the real ISO 14001 please stand up?' Civ.Eng. (N.Y.), 67(11), $45-47$

Lexington Group. (2002). Proyecto Adminis- tración Ambiental Monterrey, <http://www.cec.org/pubs_docs/scope/index.cfm?varlan=english\&ID=15> (under Reports section)

Marsh, James, \& Perera, Terrence (2012). The ISO 14001 Standard: analysis into its strengths and weaknesses, and potential opportunities for deployment by tomorrow's global business. International Journal of Environmental, Cultural, Economic, and Social Sustainability, 6(3), 23-36

Matthews, D. H. (2001). Assessment and design of industrial environmental management systems, PhD dis., Department of Civil and Environmental Engineering, Carnegie Mellon University, Pittsburgh

Matthew Franchett (2011). ISO 14001 and solid waste generation rates in US manufacturing organizations: an analysis of relationship, Journal of Cleaner Production, 19, 1104-1119. https://doi.org/10.1016/j.jclepro.2011.01.004

Pinero E., \& Mason, P. (1998). A Case Study: ISO 14000 - Benefits To The Bottom Line http://www.p2pays.org/ref/01/00844.pdfp7

Rondinelli, D., \& Vastag, G. (2000). Common sense, or just a label? - The value of ISO 14001 environmental management systems. European Management Journal, 18, 499-510. http://dx.doi.org/10.1016/S0263-2373(00)00039-6

Russo, M. V. (2000). Institutional change and theories of organizational strategy: ISO 14001 and toxic emissions in the electronic industry. Paper presented at the 60th annual meeting of the Academy of Management, Toronto.

Successful Practices of Environmental Management Systems in Small and Medium-Size Enterprises, Commission for Environmental Cooperation - A North American Perspective ISBN: 2-923358-29-5(C) Commission for Environmental Cooperation, 2005

Yarnell, P. (1993). Implementing an ISO 14001 Environmental Management System: A Case Study of Environmental Training and Awareness at the Vancouver International Airport Authority, http:www.rem.sfu.ca/pdf/yarnell.pdf 


\section{Macrothink \\ Environmental Management and Sustainable Development \\ ISSN 2164-7682 \\ 2017, Vol. 6, No. 2}

\section{Copyright Disclaimer}

Copyright for this article is retained by the author(s), with first publication rights granted to the journal.

This is an open-access article distributed under the terms and conditions of the Creative Commons Attribution license (http://creativecommons.org/licenses/by/3.0/). 